\title{
Learning Management System Personalization based on Multi-Attribute Decision Making Techniques and Intuitionistic Fuzzy Numbers
}

\author{
Jorge Luna-Urquizo \\ Universidad Nacional de San Agustín de Arequipa \\ Arequipa, Perú
}

\begin{abstract}
The personalization of Learning Management Systems is a fundamental task in the current context of e-Learning and the WWW. However, there are many controversies around the criteria used to make the selection and presentation of the most appropriate content for each user. The most used approaches in the last decade were the identification of learning styles, the analysis of the history and navigational behavior, and the classification of user profiles, without finding conclusive evidence to determine a method that can be adopted universally, considering the complexity of the cognitive processes involved. This paper proposes an approach based on multi-attribute decision making techniques, which allows considering and combining the criteria most effectively used in the area, according to particular contexts, as a new approach to the content personalization and appropriate learning objects selection. The application of this approach aims to maximize the effectiveness and efficiency of the teaching process and enrich the user experience.
\end{abstract}

Keywords-Learning Management Systems (LMS); e-Learning; multi-attribute decision making; learning styles; content personalization; learning objects selection

\section{INTRODUCTION}

Over the last decade, online learning environments, such as e-Learning platforms, Massive Open Online Courses (MOOC's), and educational mobile applications, as well as the amount of resources available on the WWW, have grown exponentially, facilitating access to education at all levels and employability skills training. However, this has also made it increasingly difficult to find, select and customize the contents, activities and experiences most appropriate for the needs of each user, according to their individual characteristics, which constitutes an essential requirement to achieve meaningful learning effectively.

It is for this reason that researchers in the area have been developing various techniques, tools, and models focused on the personalization of learning management systems (LMS), the most widely used being the identification of learning styles (LS), the analysis of the history and navigational behavior, the classification according to user profiles, among others. However, there are still many controversies about the effectiveness of the criteria used, and little conclusive evidence that allows the generalization of these approaches, or the convergence towards some method that can be universally adopted, considering the complexity of cognitive processes and diversity typical of human nature.

In accordance with this, new trends in education, such as project-based learning, problem-based learning, or the competency-based approach; the different approaches and theories presented in recent years; and the evidence of the most recent case studies, seem to point to the need to consider other strategies for the appropriate selection of contents, or combinations thereof, as well as the attributes of each learning object to be used or task to solve. According to [1]: "while there is no one perfect way, teachers across the globe strive to identify a right mix of pedagogies to effectively capitalize on the learning capacity and styles of the new generation of college students".

This paper proposes a novel approach to improve the implementation and customization of LMS, which allows combining the most important and relevant educational approaches and strategies in the area, through an evaluation scheme that can be adapted to each particular context and educational level, together with the profile of each student (individual characteristics), as well as a mechanism to correlate these attributes with the learning objects and main activities available on the most used LMS platforms, in order to achieve a high level of customization.

The importance of this approach is that it will facilitate the implementation of personalized learning environments that enrich the user experience and maximize the efficiency of the teaching / learning process. One of the limitations of the proposed approach is that, by combining different approaches and techniques, it requires the participation of experts who master all the techniques considered and can give an opinion regarding them, as well as a specialized repository of learning objects with a great diversity of resources, which could delay its implementation.

The rest of the paper is organized as follows. Section 2 presents a literature review and related works; Section 3 details the proposed model, including the definition of the user profile and the proposed method for the selection of learning objects, as well as other resources and activities, and Section 4 presents the conclusions of this research.

\section{RELATED WORK}

The identification of LS has been one of the most widely used approaches for the design and implementation of adaptive systems and LMS. According to Nafea et.al. [2], several studies indicate that "adaptive e-learning environments based on specific LS are not only more productive, but also create higher student satisfaction levels, decrease learning times, and increase students academic achievement", while in the opposite 
case: "students with a strong preference for a specific LS have difficulty learning when it is not supported by the teaching environment" [2]. For Ali et al. [3], LS "can be considered as a valuable factor for enhancing learning process by adopting an effective learning technology", so various authors agree that "personalized learning is a key in the field of e-Learning" [3].

In this regard, there are different classifications of LS, as well as different techniques to determine the particular LS of a student. Theoretically, the predominant LS is the one that would allow him to maximize the efficiency of the learning process. These techniques range from the most traditional approaches as the psychological questionnaires or tests, up to the methods of automatic detection or prediction, based on Artificial Intelligence and data mining techniques, such as the proposals by [2], [3], [4], [5], [6]. Within the review of related works, carried out for the present work, the methods proposed by Alfaro et al. [7], Aguilar et al. [8], and Seyal et al. [9], have been particularly considered, and will be briefly described in the following paragraphs.

Alfaro et al. [7], presents an approach based on neural networks and fuzzy logic, used to automatically identify the LS of each student, analyzing their interactions within the platform through the log-file, and to go reviewing and updating the identification made over time. To do this, the authors identified the relationship between the different LS, based on the Honey-Alonso model, and the main categories of resources and activities available on the Moodle platform, which are similar in the most used LMS around the world. This tool serves as an instrument for analyzing the user's behavior and choices within the platform. The authors also considering the cases in which the students are more adaptable to any LS, and the cases in which erratic behaviors occur in a single learning session, which do not affect the overall behavior, obtaining acceptable results compared to other techniques.

In Aguilar et al. [8], Social Learning Analytics (SLA) is used, wich "focuses mainly on the analysis of social networks (SNA) and the WWW, to obtain hidden information in large amounts of data (Big Data), and discover patterns of interaction and behavior of educational social actors", with the objective of determining the particular LS of each student. The importance of this approach is that it allows obtaining a point of view outside the learning environment, considering the interactions of the subject in "situations with greater freedom of action and greater diversity of resources" [8]. This work involves concepts such as Big Data, Semantic Mining, Text Mining, Data Mining, among others domains. Similarly, the approach proposed by Hamdaoui et al. [10] could be applied, where a game is used to collect "certain metrics and information susceptible of monitoring the player's interactions in the game", with which it is possible to make a correlation of students behaviour with LS, in a context totally different from LMS or other conventional learning tools.

Seyal et al. [9] proposes to examine "the relationship between students' personality traits and LS". For this purpose, the authors applied a quantitative survey, based on a random sampling approach, and the results were analyzed using statistical techniques, such as Chi-square test, the Bigfive (Ocean) personality theory, to investigate the student's personality traits, and the VARK LS model, to investigate the student's LS preferences, establishing certain relationships between both domains. This study aims to helping educators to design an develop "an effective teaching/learning style as a rewarding one other than focusing on the traditional classroom environment". According to [9], "when the educator's teaching methods match the learning styles of the students, the chance for them to learn easily and understand quickly can be advantageous to their university ranking due to high rate of degree achievement".

While there are a large number of case studies and published articles about the application and efficiency of LS in the learning process, such as those presented in [2], [3], [4], [5], [6], [7], [8], [10], [9], [11], [12], [13], [14], their efficiency has been highly questioned. The most recent studies seem to indicate that there is insufficient evidence to consider that the LS concept, by themselves, can have a significant impact on the learning process or in the knowledge retention process, as mentioned in [15], [16], [17], [18], [19], [20], [21]. There are even discussions on the validity of the methods used as a reference, as well as the controversy over whether LS they are "fixed, biologically determined and inflexible dispositions, or if they are dynamic, adaptable and flexible characteristics" [22]. However, since its use is very widespread, so you should not lose sight of this approach.

Another approach to consider, whose use has been gaining strength in recent years, is the Cognitive Load Theory (CLT), which uses an information processing approach to cognition, based on the human cognitive architecture. According to Moussa-Inaty et al. [23], CLT "was a better predictor of student performance than student LS", but at the same time maintains a partial relationship with said theory, especially evidenced in multimedia learning environments, as stated in [24]. According to [25], CLT “ it is a major theory providing a framework for investigations into cognitive processes and instructional design". One of the advantages of the CLT approach is that it considers simultaneously the structure of information and the cognitive architecture that allows learners to process that information.

This approach has been successfully applied in the achievement of complex learning, taking into account student experience, and allowing differentiate and prioritize between several learning objectives in progress [26], in simulation-based education applications such as [27], [28], multimedia learning with different objective measures [29], game-based learning approaches [30], among others. However, this approach, as well as the techniques commonly associated with it, also has some shortcomings, for example, according to [31]: "recent developments in CLT suggest that the human motor system plays an important role in cognition and learning; however, it is unclear whether models of working memory (WM) that are typically espoused by CLT researchers can reconcile these novel findings".

The research in affective computing seeks to understand and manage the influence of the affective or emotional factors of the person during their interaction with the technology. LMS are not out of this approach, the most important factors being the influence of the emotions and personality of the student. For Jarvenoja [32], "emotions usually manifest themselves in collaborative scenarios or discussion groups, and can influence learning". According to Matthews [33]: "Personality traits are dispositions towards action, belief and attitude formation, dif- 
fer across individuals and influence behavior" and in practice, "they can modulate the way in which the student participates in a given situation" [34]. For Santos [35], affective computing could help to "enrich the personalized support provided in online educational settings by taking into account the influence that emotions and personality have in the learning process", and delivery of the "appropriate affective support in diverse educational settings".

Nafea et al. [2], presents the concept of Learning Behavior Patterns, which are defined using three variables: (i) the time spent on each LO; (ii) the number of messages sent; (iii) the format of the LOs accessed during a session. These variables are correlated by a set of equations, and used as inputs for an algorithm called "learning style adaptation algorithm" [2], taking as reference the Felder and Silverman LS model. Such research proposes an architecture based on four stages: information retrieval (system log-file analysis), dynamic checking sessions (profile construction), profile adaptation phase, and updating student profile after each learning session, in order to establish a user profile based on LS and user behavior within an LMS, the which is updated after each learning session, and is evaluated using two metrics: Mean Absolute Error (MAE) and Root Mean Squared Error (RMSE).

Another approach used in this study is the Learning Progressions (LP), which is defined by Plummer [36], as "the meaningful sequencing of teaching and student learning expectations accounted for across disciplines, student developmental stages, and grades". LP provide a scope and a work plan for teachers to develop student knowledge and skills. According to [37], LP are characterized by two traits: “(i) Standards intended to address student abilities, social, emotional, and physiological needs; (ii) Sequence of standards to meet necessary expectancy and actualization". The LP approach uses the concepts of nodes and subnodes, where "each learning node in the progression depicts knowledge and/or skills a student must attain before moving along the learning spectrum", and the concept of construct maps, defined by [38] as: "representations of models of cognition by which the results of the assessment can be interpreted".

In an integrated framework, many of the approaches mentioned above could be considered as criteria or attributes, and then, the problem of combining and evaluating multiple alternatives based on these approaches, to find the best options for a student in particular within an LMS, lies in the theory of decision making with multiple attributes (MADM). This theory is one of the most important techniques used in the business administration and financial field in recent years, as can be seen in [39], [40], [41], [42]. This approach has also recently been used in other areas such as the petrochemical industry, heterogeneous wireless networks, sustainable renewable energy development, satellite layout, among others.

For example, in Budiharjo et.al. [43], MADM is applied in selecting the best elementary school, considering criterias such as teacher information, student information, number of courses, infrastructure, among others. Purnomo and Rozi [44], uses weighted product (wp) and simple additive weighting (saw) methods in the best graduation selection system. In Perez et al. [45] the diffusion intuitionist dimensional analysis is applied to the selection of suppliers within the supply chain, considering various criteria such as delivery time, load capacity, cost, repeatability, quality of service, and programming flexibility, with the objective of "establishing competitive advantages for the company" [45].

According to Keshavarz et al. [46], MADM problems usually involve discrete decision variables and a limited number of alternatives for evaluation, so that "uncertainty is an inevitable part of information when the evaluation process is performed by human judgement". For this reason, this type of problems usually also involves the use of fuzzy logic to capture the uncertainty of evaluation processes. However, according to Perez et al. [45], in recent years the intuitionistic fuzzy sets (IFS) have gained ground replacing the classic fuzzy sets, "due to their greater ability to deal with vague information and in environments of uncertainty", especially in combination with other decision making support techniques, such as MADM.

According to [47], a IFS is "characterized by a membership function and a non-membership function, which is a generalization of the concept of fuzzy set whose basic component is only a membership function", and represents a a powerful tool to deal with vagueness. There are currently several variants of the IFS, such as: Interval-Valued IFS (IVIFS), Neutrosophic Sets (NS), Interval type-2 Fuzzy Sets, Intuitionistic fuzzy parameterized soft set, Intuitionistic Hesitant Fuzzy Sets (HFS), Tolerance-based intuitionistic fuzzy-rough set Intuitionistic Fuzzy Topological Spaces, etc. In general, an IFS can be defined according to the Equation 1.

$$
A=\left\{\left\langle x, \mu_{A}(x), \nu_{A}(x)\right\rangle \mid x \in X\right\}
$$

where:

$$
\begin{gathered}
\mu_{A}: X \rightarrow[0,1] \\
\nu_{A}: X \rightarrow[0,1]
\end{gathered}
$$

with the condition:

$$
0 \leqslant \mu_{A}(x)+\nu_{A}(x) \leqslant 1
$$

The numbers $\mu_{A}(x)$ and $\nu_{A}(x)$ represent, respectively, the membership degree and non-membership degree of the element $x$ to the set $A$.

Kurilovas [48], presents a similar approach to the proposed, using techniques such as learning analytics and multiple criteria decision analysis, "testing with different weights of evaluation criteria on empirical data" [48]. For this purpose, the author uses an ad-hoc methodology based on the assessment of suitability, acceptance and use of personalized learning units (LU), defined as "methodological sequences of components or learning objects" [48], taking as reference the Educational Technology Acceptance \& Satisfaction Model (ETAS-M), and the Felder-Silverman LS Model (FSLSM), both approaches widely accepted. The approach presented in this paper differs from the previous one in terms of the attributes considered as part of the student's profile, the selection criteria, and the operators used for decision making.

ETAS-M Model is used as a decision-making methodology aimed at assessing the applicability, acceptance and use of custom LOs, and is an extension of the Unified Theory 
on Acceptance and Use of Technology (UTAUT) model, considering the premise that "usability aspects of e-learning systems cannot be treated independently from their impact on learning behavior and the pedagogical setting in which they are implemented" [49]. In UTAUT there are 7 artefacts designed to determine the intention to use one or more components of a model, of which, Kurilovas [48] considers that "four of them have a significant role for the analysis of LOs and LMS content personalization":
1) Performance expectancy (PE)
2) Effort expectancy (EE)
3) Social influence (SI)
4) Facilitating conditions (FC).

The first three factors are direct determinants of the intention to use the technology (LMS), and the last one is a direct determinant of user behavior. For the application of the model, factors of gender, age, experience, among others, are considered to moderate the impact of these four artifacts. In ETAS-M [49], influence of pedagogical paradigm (IPP) is proposed instead of social influence (SI) criteria in UTAUT. For [48], one of the advantages of this kind of model is that "not require specific high-level technological expertise from experts evaluators".

Regarding the collection and analysis of input data, regardless of the models and techniques to be used, one of the most commonly used approaches is Learning Analytics, which according to [48], "are known as the measurement, collection, analysis, and reporting of data about learners and their contexts to understand and optimize learning and environments in which it occurs". In addition to being focused on learning, it is a discipline that interacts with others of great relevance in this decade such as educational data mining (EDM), business intelligence (BI), social network analysis (SNA) and related Machine Learning (ML).

For the application in education, the basic tasks of LA should be at least:

1) Clasification: to classify each student in a classroom into one of predefined set of students group.

2) Clustering: "to determine studentes group that need special course profiling" [48].

3) Association rules: "to discover interesting relations between course elements which were used by particular students" [48].

4) Prediction: "to predict dependencies of using learning environment's activities/tools and final student's learning outcomes" [48].

5) Decision tree of students' actions. According to Kurilovas [48], "the decision tree algorithm automates and integrates the entire hypothesis generation process and evaluates the result, and are able to handle primary data with a little or no preprocessing data action". For example, in Kurilovas [48], the analysis was performed choosing student's ID as a target subject.

The approach presented in this paper is initially oriented towards traditional LMS, however, there is the possibility of applying it in future works with other technologies, such as: cloud-based student-centric context-aware systems [50], integrated gamification models in E-environments Learning (E-MIGA) [51], interactive e-learning with integrated virtual reality (VR) [52], STEM e-Learning in an Immersive VR Environment [53], and even in learning environments or tools based on virtual reality using wearable head-mounted displays (HMDs) [54], among others.

\section{PROPOSED MODEL}

The proposed model comprises two main components: (i) the user's profile, which is adaptive and evolves over time, (ii) the mechanism for evaluation and selection of Learning Objects and Learning activities (alternatives), which is based on MADM, using the attributes of the user profile, in order to select the most appropriate learning contents.

The model uses the open source LMS Moodle platform for the presentation of the selected contents and the interaction with the users, since it is one of the most used platforms around the world, while the feedback for the model is obtained from the analysis of user behavior (interactions with the system), through $\log$-file analysis.

\section{A. Student Profile}

The student's profile is defined by a set of attributes (criteria), which must be applicable to evaluate all of the proposed alternatives (LOs), and at the same time they must be differentiators, since if an attribute or criterion is similar for several alternatives will not serve as a discard mechanism. Table I details the attributes defined for the construction of the student's profile.

\section{B. Method of Evaluation and Selection of Learning Objects}

The mechanism of selection and evaluation of LO's is based on diffuse multi-attribute intuitionist dimensional analysis techniques, for which it is necessary to define the following sets:

- $O=\left\{O_{1}, O_{2}, \ldots, O_{n}\right\}$, as the set of learning objects and learning activities defined for a given learning unit or skill to develop, which are stored in a specialized repository, and represent the alternatives to evaluate.

- $A=\left\{A_{1}, \ldots, A_{n}\right\}$, as the vector that contains the values or linguistic labels defined for each of the $A_{x}$ attributes of the student's profile (Table I), which represent the criteria to evaluate.

- $D M=\left\{D M_{1}, \ldots D M_{l}\right\}$, which represents the set of decision makers, who can be experts in education, teachers in the area, educational psychologists or other related stakeholders.

- $W=\left\{w_{1}, \ldots w_{m}\right\}^{T}$, which represents the vector of the relative weights for each of the attributes of the user profile, according to the opinion of the experts (decision makers).

For the application of the MADM approach, as a first step, it is necessary to determine the importance of each decision 
TABLE I. ATTRIBUTES DEFINED FOR THE CONSTRUCTION OF THE STUDENT PROFILE

\begin{tabular}{|c|c|}
\hline Attributes & Description \\
\hline ID & $\begin{array}{l}\text { Unique identifier for each student, which al- } \\
\text { lows to relate to their personal data record, and } \\
\text { reuse the student profile with other models and } \\
\text { educational tools. }\end{array}$ \\
\hline Age & $\begin{array}{l}\text { Stores the student's date of birth, from which } \\
\text { the age of student can be calculated easily and } \\
\text { quickly whenever necessary. } \\
\text { This is important because certain LOs could } \\
\text { be more appropriate according to the age } \\
\text { range of the learner, and even more signifi- } \\
\text { cant, when understanding historical situations } \\
\text { or contexts more in line with the experiences, } \\
\text { and at the other extreme, some LOs could } \\
\text { be difficult to understand due to jargon or } \\
\text { examples unknown to the apprentice. }\end{array}$ \\
\hline $\begin{array}{l}\text { LMS Learning } \\
\text { Style }\end{array}$ & $\begin{array}{l}\text { It stores, and keeps updated, the preferred LS } \\
\text { of each student, identified from the analysis } \\
\text { of their interactions within the LMS (user } \\
\text { behaviour), using the method proposed by } \\
\text { Alfaro et al. [7], based on neural networks } \\
\text { and fuzzy logic, which takes as reference the } \\
\text { Honey-Alonso model. }\end{array}$ \\
\hline $\begin{array}{l}\text { Social Learning } \\
\text { Style }\end{array}$ & $\begin{array}{l}\text { Stores the LS of each student, identified from } \\
\text { their development in social networks and web- } \\
\text { sites, obtained through Social Learning An- } \\
\text { alytics techniques according to the proposal } \\
\text { of Aguilar et al. [8], which is done on large } \\
\text { amounts of data, taking as reference the Felder } \\
\text { and Silverman model. }\end{array}$ \\
\hline $\begin{array}{l}\text { Learning } \\
\text { behavior } \\
\text { patterns }\end{array}$ & $\begin{array}{l}\text { Stores the LS of each student, obtained from } \\
\text { the identification of learning behavior pat- } \\
\text { terns, based on the time spent on LO's, the } \\
\text { number of messages exchanged, and the for- } \\
\text { mat of the LO's accessed by the student, } \\
\text { according to the [2] proposal, and its equiva- } \\
\text { lence with the Felder and Silverman model. }\end{array}$ \\
\hline Personality & $\begin{array}{l}\text { Stores the student's personality type according } \\
\text { to the Five Factor Model (FFM), obtained } \\
\text { using the method proposed by Seyal et al. } \\
\text { [9]. Personality traits are dispositions towards } \\
\text { action, belief and attitude formation, differ } \\
\text { across individuals and influence behaviour, } \\
\text { and is much more stable than emotions. } \\
\text { This attribute is necessary for delivery the } \\
\text { appropriate affective support in diverse edu- } \\
\text { cational settings [35]. }\end{array}$ \\
\hline $\begin{array}{l}\text { Learning } \\
\text { Preference }\end{array}$ & $\begin{array}{l}\text { Indicates if the student has a preference for } \\
\text { some learning approach such as: individual, } \\
\text { group, cooperative, collaborative, problem- } \\
\text { based, project-based, among other, or is easily } \\
\text { adaptable to any type of approach. } \\
\text { This is important because it will allow a } \\
\text { better planning of the resources and activities } \\
\text { available within the course. }\end{array}$ \\
\hline
\end{tabular}

makers $D M_{i}$, using a linguistic term associated with a intuitionist fuzzy number (IFN), selected from the Table II. This qualification can be done taking as reference the professional experience, institutional position, level of specialization, or other factors deemed appropriate.

Then, be $D M_{k}=\left\{\mu_{k}, v_{k}, \pi_{k}\right\}$ the diffuse number of the rating of the $k^{t h}$ decisor, the weight corresponding to the
TABLE II. LINGUISTIC TERMS TO DETERMINE THE IMPORTANCE OF DMs [45]

\begin{tabular}{|l|l|}
\hline Linguistic term & IFN $(\mu, v, \pi)$ \\
\hline Beginner & $(0.1,0.9,0)$ \\
\hline Practitioner & $(0.35,0.6,0.05)$ \\
\hline Proficient & $(0.5,0.45,0.05)$ \\
\hline Expert & $(0.75,0.2,0.05)$ \\
\hline Master & $(0.9,0.1,0)$ \\
\hline
\end{tabular}

opinions of $D M_{k}$ is calculated using the equation 5, proposed by [55].

$$
\lambda_{k}=\frac{\left(\mu_{k}+\pi_{k}\left(\frac{\mu_{k}}{\mu_{k}+v_{k}}\right)\right)}{\sum_{k=1}^{l}\left(\mu_{k}+\pi_{k}\left(\frac{\mu_{k}}{\mu_{k}+v_{k}}\right)\right)}
$$

Where:

$$
\begin{gathered}
\lambda_{k} \geq 0 \\
\sum_{k=1}^{l} \lambda_{k}=1
\end{gathered}
$$

In second place, we proceed to determine the importance of each criterion or attribute of the user profile through the individual evaluation by each of the DM, using the linguistic terms shown in Table III. In general, all criteria cannot assume the same importance, and decision makers may have different opinions regarding the same criteria, which is one of the strengths of the proposed model.

TABLE III. LINGUISTIC TERMS TO DETERMINE THE IMPORTANCE OF ATtRiButes [45]

\begin{tabular}{|l|l|}
\hline Linguistic term & IFN $(\mu, v, \pi)$ \\
\hline Very Unimportant & $(0.1,0.9,0)$ \\
\hline Unimportant & $(0.35,0.6,0.05)$ \\
\hline Medium & $(0.5,0.45,0.05)$ \\
\hline Important & $(0.75,0.2,0.05)$ \\
\hline Very Important & $(0.9,0.1,0)$ \\
\hline
\end{tabular}

Once the evaluation has been carried out, the opinions of all DMs for each specific criterion are added using the IFWA (Intuitionistic Fuzzy Weighted Average) operator, proposed by [56]. In this way, be $w_{j}^{k}=\left\{\mu_{j}^{k}, v_{j}^{k}, \pi_{j}^{k}\right\}$ the Intuitionistic Fuzzy Number assigned to the $A_{j}$ criterion for the $k^{t h}$ $\mathrm{DM}$, then the weight vector of the $j$ criterion, called $w_{j}$ is calculated using the equation 8 .

$$
\begin{aligned}
w_{j}= & I F W A\left(w_{j}^{1}, w_{j}^{2}, \ldots, w_{j}^{l}\right) \\
= & \lambda_{1} \cdot w_{j}^{1} \oplus \lambda_{2} \cdot w_{j}^{2} \oplus \ldots \oplus \lambda_{l} \cdot w_{j}^{l} \\
= & {\left[1-\prod_{k=1}^{l}\left(1-\mu_{j}^{k}\right)^{\lambda_{k}}, \prod_{k=1}^{l}\left(v_{j}^{k}\right)^{\lambda_{k}},\right.} \\
& \left.\quad \prod_{k=1}^{l}\left(1-\mu_{j}^{k}\right)^{\lambda_{k}}-\prod_{k=1}^{l}\left(v_{j}^{k}\right)^{\lambda_{k}}\right]
\end{aligned}
$$


Where $w_{j}$ is a intuitionistic fuzzy number, and then, the specific weight corresponding to each criterion $A_{i}$ is calculated using the equation 5 , previously used. Later, the vector of weights obtained $W=\left\{w_{1}, w_{2}, \ldots, w_{m}\right\}$, must satisfy the following equations:

$$
\begin{gathered}
w_{j}>0 \quad(j=1,2, \ldots, m) \\
\sum_{j=1}^{m} w_{j}=1
\end{gathered}
$$

Third, each of the alternatives is rated individually by each of the DMs, using the linguistic terms and diffuse intuitionist numbers shown in Table IV.

TABLE IV. LINGUISTIC TERMS TO EVALUATE THE ALTERNATIVES (LEARNING RESOURCES) [45]

\begin{tabular}{|l|l|}
\hline Linguistic terms & IFN $(\mu, v, \pi)$ \\
\hline Extremely Bad (EB) & $(0.1,0.9,0)$ \\
\hline Very Bad (VB) & $(0.1,0.75,0.15)$ \\
\hline Bad (B) & $(0.25,0.6,0.15)$ \\
\hline Medium Bad (MB) & $(0.4,0.5,0.1)$ \\
\hline Fair (F) & $(0.5,0.4,0.1)$ \\
\hline Medium Good (MG) & $(0.6,0.3,0.1)$ \\
\hline Good (G) & $(0.7,0.2,0.1)$ \\
\hline Very Good (VG) & $(0.8,0.1,0.1)$ \\
\hline Excellent (E) & $(1,0,0)$ \\
\hline
\end{tabular}

Then, using the sets defined above, the intuitionist fuzzy decision matrix of each DM (IFDM) is constructed, denoted as $R^{k}=\left[r_{i j}^{k}\right]_{n x m}$, and subsequently all opinions of DMs are agregated using the IFWA operator (Equation 11), giving rise to the Aggregate Weighted Intuitionistic Fuzzy decision matrix (AWIFDM), which represents the evaluations, based on the opinions of the DMs, for each of the alternatives (resources) to evaluate $O_{n}$.

$$
\begin{aligned}
R= & \left(r_{i j}\right)_{n x m} \\
r_{i j}= & I F W A\left(r_{i j}^{1}, r_{i j}^{2}, \ldots, r_{i j}^{l}\right) \\
= & \lambda_{1} \cdot r_{i j}^{1} \oplus \lambda_{2} \cdot r_{i j}^{2} \oplus \ldots \oplus \lambda_{l} \cdot r_{i j}^{l} \\
= & {\left[1-\prod_{k=1}^{l}\left(1-\mu_{i j}^{k}\right)^{\lambda_{k}}, \prod_{k=1}^{l}\left(v_{i j}^{k}\right)^{\lambda_{k}},\right.} \\
& \left.\quad \prod_{k=1}^{l}\left(1-\mu_{i j}^{k}\right)^{\lambda_{k}}-\prod_{k=1}^{l}\left(v_{i j}^{k}\right)^{\lambda_{k}}\right]
\end{aligned}
$$

After which, the intuitionistic final decision matrix is defined as:

$$
R=\left[\begin{array}{ccc}
r_{11} & \cdots & r_{1 m} \\
\vdots & \ddots & \vdots \\
r_{n 1} & \cdots & r_{n m}
\end{array}\right]
$$

Or more specifically according to the form shown in the equation 13.

$$
R=\left[\begin{array}{ccc}
\left(\mu_{c_{1}}, v_{c_{1}}, \pi_{c_{1}}\right)\left(x_{1}\right) & \cdots & \left(\mu_{c_{1}}, v_{c_{1}}, \pi_{c_{1}}\right)\left(x_{m}\right) \\
\vdots & \ddots & \vdots \\
\left(\mu_{c_{n}}, v_{c_{n}}, \pi_{c_{n}}\right)\left(x_{1}\right) & \cdots & \left.\left(\mu_{c_{n}}, v_{c_{n}}, \pi_{c_{n}}\right)\left(x_{m}\right)\right)
\end{array}\right]
$$

Then the ideal solution $S=\left(x_{1}^{*}, x_{2}^{*}, \ldots, x_{m}^{*}\right)$ for the proposed problem is calculated, considering that, according to the nature of the problem, all the attributes belong to the category commonly referred to as benefits, and there is no cost category, so:

$$
\begin{aligned}
\mu_{s}\left(x_{j}\right) & =\left(\max v_{c_{i}}\left(x_{j}\right)\right) \\
v_{s}\left(x_{j}\right) & =\left(\min v_{c_{i}}\left(x_{j}\right)\right) \\
\pi_{s}\left(x_{j}\right)=1 & -\left(\mu_{s}\left(x_{j}\right)+v_{s}\left(x_{j}\right)\right)
\end{aligned}
$$

Then, the Intuitionistic Fuzzy Index of Similarity (IFIS) of the alternative $C_{i}$ is calculated with respect to the ideal solution $S$, using the equation 17 .

$$
\begin{aligned}
\text { IFIS }_{i} & =\sqrt[W]{\prod_{j=1}^{m}\left\{\frac{x_{j}^{i}}{s_{j}}\right\}^{W_{j}}} \\
& =\prod_{j=1}^{m}\left\{\frac{\mu_{c_{i}\left(x_{j}\right)}, v_{c_{i}\left(x_{j}\right)}, \pi_{c_{i}\left(x_{j}\right)}}{\mu_{s\left(x_{j}\right)}, v_{s\left(x_{j}\right)}, \pi_{s\left(x_{j}\right)}}\right\}^{W_{j}}
\end{aligned}
$$

Where:

$$
\begin{gathered}
\text { IFIS } S_{i}=\begin{array}{l}
\text { Intuitionistic Fuzzy Index of Similarity of the } \\
\text { alternative } \mathrm{i} \text {. }
\end{array} \\
s_{j}=\text { Value of the ideal solution for criterion } \mathrm{j} \\
x_{j}^{i}=\text { Value of criterion } \mathrm{j} \text { for alternative } \mathrm{i} \\
w_{j}=\text { The weight corresponding to criterion } \mathrm{j}
\end{gathered}
$$

Finally, the similarity index (IS) of a candidate $c_{i}$ with respect to the IFIS is calculated, using the equation 18 proposed by [57].

$$
I S_{i}=1-\frac{1-\mu_{I F I S_{i}}}{1+\pi_{I F I S_{i}}}
$$

Where:

$$
\begin{gathered}
I S_{i}=\text { Similarity index of the candidate } \mathrm{i} \\
\mu_{I F I S_{i}}=\text { Truth value of the candidate } \mathrm{i} \text { with respect to his } \\
\text { IFIS }
\end{gathered}
$$

$\left.\pi_{[} I F I S_{i}\right]=$ Uncertainty value of the candidate i regarding his IFIS

The highest value of IS (closer to 1), indicates the learning object that best suits the preferences and needs of a specific student at a given time, within a given topic or unit of learning, so it would be enough for the LMS to select and display the learning objects with the highest value of IS, being able to be limited to a maximum number of resources shown or through a threshold for the value of the IS. 


\section{CONCLUSION}

The proposed definition of the student profile, which considers different pedagogical approaches, cognitive strategies, and other attributes, makes possible the application of different intelligent user analysis techniques, towards the personalization of contents within LMS or similar environments.

The application of MADM techniques, mostly used in the field of administration and finance, in the evaluation and selection of learning objects, is a great help for the customization of content within LMS platforms, as long as there is enough information (variety of criteria) for the correct use of these techniques.

Intuitionistic Fuzzy Numbers represent a mechanism with a lot of potential in solving problems with a high degree of uncertainty and multiple criterias that influence the decision, such as the analysis of the user profiles and the application proposed, due to the complexity of human nature and of the related cognitive processes.

Finally, it is considered that, the use of the student profile defined in this investigation, together with MADM and IFN techniques, under the proposed method, constitute a good alternative for the selection and customization of contents within any LMS, which will allow contribute to improve the efficiency of the learning process and enrich the user experience.

The approach presented in this paper is initially oriented towards traditional LMS, however, there is the possibility of applying it in future works with other technologies, such as: gamification models in e-Learning environments, interactive elearning with virtual reality, STEM e-Learning in an Immersive VR environments, among others.

\section{ACKNOWLEDGMENT}

The author would like to thank the Universidad Nacional de San Agustín de Arequipa - Perú (UNSA), for supporting this research.

\section{REFERENCES}

[1] T. Harraf, "Effects of four varied teaching pedagogies on freshmen student success," Proceedings of International Academic Conferences, jun 2019.

[2] S. M. Nafea, F. Siewe, and Y. He, "A novel algorithm for dynamic student profile adaptation based on learning styles," in Advances in Intelligent Systems and Computing, pp. 29-51, Springer International Publishing, aug 2019.

[3] N. A. Ali, F. Eassa, and E. Hamed, "Adaptive e-learning system based on personalized learning style," Journal of Fundamental and Applied Sciences, vol. 10, pp. 246-251, Mar. 2018.

[4] I. Azzi, A. Jeghal, A. Radouane, A. Yahyaouy, and H. Tairi, "A robust classification to predict learning styles in adaptive e-learning systems," Education and Information Technologies, aug 2019.

[5] J. Bernard, T.-W. Chang, E. Popescu, and S. Graf, "Learning style identifier: Improving the precision of learning style identification through computational intelligence algorithms," Expert Systems with Applications, vol. 75, pp. 94-108, jun 2017.

[6] Özcan Özyurt and H. Özyurt, "Learning style based individualized adaptive e-learning environments: Content analysis of the articles published from 2005 to 2014," Computers in Human Behavior, vol. 52 , pp. 349-358, nov 2015.
[7] L. Alfaro, C. Rivera, J. Luna-Urquizo, E. Castaneda, and F. Fialho, "Utilization of a neuro fuzzy model for the online detection of learning styles in adaptive e-learning systems," International Journal of Advanced Computer Science and Applications (IJACSA), vol. 9, no. 12, 2018.

[8] J. Aguilar, O. Buendia, A. Pinto, and J. Gutiérrez, "Social learning analytics for determining learning styles in a smart classroom," Interactive Learning Environments, pp. 1-17, aug 2019.

[9] A. Seyal, N. Z. Siau, and W. S. H. Suhali, "Evaluating students' personality and learning styles in higher education: Pedagogical considerations," International Journal of Learning, Teaching and Educational Research, vol. 18, pp. 145-164, jun 2019.

[10] N. Hamdaoui, M. K. Idrissi, and S. Bennani, "Modeling learners in educational games: Relationship between playing and learning styles," Simulation \& Gaming, vol. 49, pp. 675-699, jul 2018.

[11] N. Jalaledin, M. A. MAHMOOD, and F. Somayeh, "Classification of learning styles using behavioral features and twin support vector machine," JOURNAL OF TECHNOLOGY OF EDUCATION, vol. 13, no. 3, pp. 459-469, 2019.

[12] K. Crockett, A. Latham, and N. Whitton, "On predicting learning styles in conversational intelligent tutoring systems using fuzzy decision trees," International Journal of Human-Computer Studies, vol. 97, pp. 98-115, jan 2017.

[13] M. A. Palomino, M. Strefezza, and L. Contreras, "Sistema difuso para la detección automática de estilos de aprendizaje en ambientes de formación web," Ciencia, Docencia y Tecnología, vol. 27, pp. 269-294, May 2016.

[14] H. M. Truong, "Integrating learning styles and adaptive e-learning system: Current developments, problems and opportunities," Computers in Human Behavior, vol. 55, pp. 1185-1193, feb 2016.

[15] A. M. Brown and A. N. Kaminske, Five Teaching and Learning Myths-Debunked. Routledge, apr 2018.

[16] P. A. Kirschner, "Stop propagating the learning styles myth," Computers \& Education, vol. 106, pp. 166-171, 2017.

[17] S. Moser and J. Zumbach, "Exploring the development and impact of Learning Styles: An empirical investigation based on explicit and implicit measures," Computers \& Education, vol. 125, pp. 146-157, oct 2018.

[18] P. Newton, "Learning styles and evidence-based approaches to education," FASEB Journal, vol. 33, apr 2019.

[19] M. Papadatou-Pastou, M. Gritzali, and A. Barrable, "The learning styles educational neuromyth: Lack of agreement between teachers judgments, self-assessment, and students intelligence," Frontiers in Education, vol. 3, nov 2018.

[20] R. Wang and C. Liu, "The relation of dental students' learning styles to their satisfaction with traditional and inverted classroom models," $B M C$ Medical Education, vol. 19, aug 2019.

[21] D. T. Willingham, "Ask the cognitive scientist: Does tailoring instruction to "learning styles" help students learn?" American Educator, vol. 42 , no. 2 , pp. $28-32,2018$.

[22] S. Cassidy, "Learning styles: An overview of theories, models, and measures," Educational Psychology, vol. 24, pp. 419-444, aug 2004.

[23] J. Moussa-Inaty, , F. Atallah, M. Causapin, and and, "Instructional mode: A better predictor of performance than student preferred learning styles," International Journal of Instruction, vol. 12, pp. 17-34, jul 2019.

[24] Ünal Çakiroğlu, M. Güler, M. Atabay, and M. Güler, "Connections between learning styles and perceived cognitive load in multimedia learning: An experimental study," Journal of Educational Technology Systems, p. 004723951984450, apr 2019.

[25] F. Paas, A. Renkl, and J. Sweller, "Cognitive load theory and instructional design: Recent developments," Educational psychologist, vol. 38, no. 1, pp. 1-4, 2003.

[26] S. Kalyuga and A.-M. Singh, "Rethinking the boundaries of cognitive load theory in complex learning," Educational Psychology Review, vol. 28, pp. 831-852, dec 2015.

[27] K. L. Fraser, P. Ayres, and J. Sweller, "Cognitive load theory for the design of medical simulations," Simulation in Healthcare: The Journal of the Society for Simulation in Healthcare, vol. 10, pp. 295-307, oct 2015. 
[28] L. M. Naismith and R. B. Cavalcanti, "Validity of cognitive load measures in simulation-based training: a systematic review," Academic Medicine, vol. 90, no. 11, pp. S24-S35, 2015.

[29] A. Korbach, R. Brunken, and B. Park, "Measurement of cognitive load in multimedia learning: a comparison of different objective measures," Instructional Science, vol. 45, pp. 515-536, apr 2017.

[30] C.-C. Chang, C. Liang, P.-N. Chou, and G.-Y. Lin, "Is Game-based learning better in flow experience and various types of Cognitive Load than non-game-based learning? Perspective from Multimedia and Media richness," Computers in Human Behavior, vol. 71, pp. 218-227, 2017.

[31] S. Sepp, S. J. Howard, S. Tindall-Ford, S. Agostinho, and F. Paas, "Cognitive load theory and human movement: Towards an integrated model of working memory," Educational Psychology Review, vol. 31, pp. 293-317, feb 2019.

[32] H. Järvenoja and S. Järvelä, "Emotion control in collaborative learning situations: Do students regulate emotions evoked by social challenges," British Journal of Educational Psychology, vol. 79, no. 3, pp. 463-481, 2009.

[33] G. Matthews and S. E. Campbell, "Sustained performance under overload: Personality and individual differences in stress and coping," Theoretical Issues in Ergonomics Science, vol. 10, no. 5, pp. 417-442, 2009.

[34] A. Solimeno, M. E. Mebane, M. Tomai, and D. Francescato, "The influence of students and teachers characteristics on the efficacy of faceto-face and computer supported collaborative learning," Computers \& Education, vol. 51, no. 1, pp. 109-128, 2008.

[35] O. C. Santos, "Emotions and personality in adaptive e-learning systems: An affective computing perspective," in Human-Computer Interaction Series, pp. 263-285, Springer International Publishing, 2016.

[36] J. D. Plummer and J. Krajcik, "Building a learning progression for celestial motion: Elementary levels from an earth-based perspective," Journal of Research in Science Teaching, vol. 47, no. 7, pp. 768-787, 2010.

[37] L. A. Annetta, R. Lamb, D. Vallett, and M. Shapiro, "Project-based learning progressions: Identifying the nodes of learning in a projectbased environment," in Contemporary Technologies in Education, pp. 163-181, Springer, 2019.

[38] N. J. Brown and M. Wilson, "A model of cognition: The missing cornerstone of assessment," Educational Psychology Review, vol. 23, no. 2, p. 221, 2011.

[39] Y. Melia, "Multi attribute decision making using simple additive weighting and weighted product in investment," International Academic Journal of Business Management, vol. 3, no. 7, pp. 1-55, 2016.

[40] S. Fenny, A. Nursikuwagus, and T. Hartono, "Rank computation model for distribution product in fuzzy multiple attribute decision making," TELKOMNIKA, vol. 16, no. 1, pp. 274-281, 2018.

[41] A. Rucitra, "Application of multi attribute failure mode analysis of milk production using analytical hierarchy process method," in IOP Conference Series: Earth and Environmental Science, vol. 131, p. 012022, IOP Publishing, 2018.

[42] N. Kumar, T. Soota, N. Gupta, and S. K. Rajput, "Multi attribute outranking approach for supplier selection," in IOP Conference Series: Materials Science and Engineering, vol. 404, p. 012008, IOP Publishing, 2018.
[43] Budiharjo, A. P. Windarto, and A. Muhammad, "Comparison of weighted sum model and multi attribute decision making weighted product methods in selecting the best elementary school in indonesia," International Journal of Software Engineering and Its Applications, vol. 11, no. 4, pp. 69-90, 2017.

[44] A. S. Purnomo and A. F. Rozi, "Comparative analysis uses weighted product (WP) and simple additive weighting (SAW) methods in the best graduation selection system," Sebatik Journal, vol. 23, no. 1, pp. 44-52, 2019.

[45] L. Pérez, A. Alvarado, J. L. García, and O. O. Vergara, "Selección de proveedores con análisis dimensional difuso intuicionista," Cultura Cientifica y Tecnológica - CULCyT, vol. 12, pp. 136-145, Dec. 2015.

[46] M. Keshavarz Ghorabaee, M. Amiri, E. K. Zavadskas, and J. Antucheviciene, "Supplier evaluation and selection in fuzzy environments: A review of madm approaches," Economic research-Ekonomska istraživanja, vol. 30, no. 1, pp. 1073-1118, 2017.

[47] G. Wei and J. M. Merigó, "Methods for strategic decision-making problems with immediate probabilities in intuitionistic fuzzy setting," Scientia Iranica, vol. 19, no. 6, pp. 1936-1946, 2012.

[48] E. Kurilovas, "Advanced machine learning approaches to personalise learning: learning analytics and decision making," Behaviour \& Information Technology, vol. 38, pp. 410-421, nov 2018.

[49] P. Wessa, S. Poelmans, K. Milis, and E. Van Stee, "Modeling educational technology acceptance and satisfaction," Proceedings of EDULEARN09 (on cd-rom), 2010.

[50] P. Moore, Z. Zhao, and H. V. Pham, "Towards cloud-based personalised student-centric context-aware e-learning pedagogic systems," in Advances in Intelligent Systems and Computing, pp. 331-342, Springer International Publishing, jun 2019.

[51] Á. Torres Toukoumidis, L. M. Romero Rodríguez, and M. A. Pérez Rodríguez, "Modelo teórico integrado de gamificación en ambientes e-learning (e-miga).," Revista Complutense de Educación, vol. 29, no. 1, pp. 129-145, 2018.

[52] N. P. Doe, R. John, M. Sitti, and N. Thirunavukkarasu, "Interactive e-learning with integrated virtual reality," Journal of Innovation in Computer Science and Engineering (JICSE), vol. 8, no. 1, pp. 1-5, 2018.

[53] C. B. Rogers, H. El-Mounayri, T. Wasfy, and J. Satterwhite, "Assessment of stem e-learning in an immersive virtual reality (vr) environment," ASEE, 2018.

[54] C. wen Shen, J. tsung Ho, P. T. M. Ly, and T. chang Kuo, "Behavioural intentions of using virtual reality in learning: perspectives of acceptance of information technology and learning style," Virtual Reality, vol. 23, pp. 313-324, may 2018.

[55] F. E. Boran, S. Genç, M. Kurt, and D. Akay, "A multi-criteria intuitionistic fuzzy group decision making for supplier selection with TOPSIS method," Expert Systems with Applications, vol. 36, pp. 11363-11368, oct 2009.

[56] Z. Xu, "Intuitionistic fuzzy aggregation operators," IEEE Transactions on Fuzzy Systems, vol. 15, pp. 1179-1187, dec 2007.

[57] S.-f. Zhang and S.-y. Liu, "A gra-based intuitionistic fuzzy multi-criteria group decision making method for personnel selection," Expert Systems with Applications, vol. 38, no. 9, pp. 11401-11405, 2011. 